these altitudes by reaction (3) is mainly removed by photolysis.

Thus recent estimates of ozone depletion from $\mathrm{NO}_{x}$ injected above $20 \mathrm{~km}$ are not likely to be much changed. For nitrogen oxides from Concorde and high altitude subsonic aircraft, such as the Boeing-747 SP, operating at altitudes up to $18 \mathrm{~km}$, however, Thrush said that a slight ozone increase rather than a depletion might be expected. At these altitudes photolysis of nitric acid becomes less effective. Thus higher $\mathrm{OH}$ concentrations make the reaction

$\mathrm{HNO}_{3}+\mathrm{OH} \rightarrow \mathrm{H}_{2} \mathrm{O}+\mathrm{NO}_{3}$ (not shown in the figure)

compete significantly with photolysis of $\mathrm{HNO}_{3}$. Subsequent photodissociation processes such as

$$
\begin{gathered}
\mathrm{NO}_{3}+\text { visible light } \rightarrow \mathrm{NO}_{2}+\mathrm{O} \\
\text { and } \\
\mathrm{NO}_{2}+\text { near ultraviolet light } \rightarrow \mathrm{NO}+\mathrm{O}
\end{gathered}
$$

lead to the production of atomic oxygen and hence increased ozone. Increased $\mathrm{NO}_{2}$ concentrations are likely to yield additional oxygen atoms through photodissociation.

Thrush pointed out that more laboratory studies, particularly of other poorly-understood reactions involving $\mathrm{HO}_{2}$ might well yield more surprises.

\section{Light in the middle of the tunnel}

\section{from Michael T. Flanagan}

THE study of the molecular mechanism of active transport across biological membranes has followed the general pattern evolved in the study of the mechanism of action of the soluble enzymes. In this it is hoped that structural studies and kinetic studies will, when they become detailed enough, fruitfully fuse leading to a clear and precise model. Unfortunately the signals monitored in kinetic work, for example, fluorescence emission, often have such low structural information content that they cannot be unequivocally identified with a local rearrangement and the signals monitored in high resolution structural work, such as X-ray diffraction, take too long to collect to be of use in characterising transient species. In the case of intrinsic membrane proteins there is the added difficulty that it is

\title{
Abnormal conditions, normal earthquakes
}

\author{
from Peter J. Smith
}

THE point (or more accurately the zone) at which three tectonic plate boundaries meet is known as a triple junction. At about $25^{\circ} \mathrm{S}, 70^{\circ} \mathrm{E}$ in the central Indian Ocean, for example, the African, Indian and Antarctic plates come together to form a triple junction of the ridge-ridge-ridge type at which the three boundaries are all oceanic ridges with, in this case, three quite different spreading rates. Triple junctions are evidently complicated features at which the normal ridge thermal structure and stress fields may be modified. They may also be unstable, changing their positions in response to the three-plate interaction. But what effect, if any, does this complexity and/or instability have on the earthquakes generated in the vicinity of a triple junction? Are the source characteristics of nearjunction earthquakes comparable to, or demonstrably different from, those of shocks elsewhere on the ridge system?

To find out, Solomon et al. (Geophys. Res. Lett. 4, 597; 1977). have monitored microseismicity near the Indian Ocean triple junction with an ocean bottom seismometer. During the two weeks of observation 38 earthquakes were detected, fairly evenly distributed in time; and of these, 17 were local events within epicentral distances of $5-40 \mathrm{~km}$ and with local magnitudes $\left(M_{L}\right)$ in the range $0-1.5$. For each of the 17 earthquakes, seismic moment and equivalent fault length were deduced from the $\mathrm{S}$ wave amplitude spectrum.

To discover whether or not the triple junction microearthquakes were anomalous, Solomon and his colleagues then plotted seismic moment against inferred fault length (log-log plot) not just for these events but also

often impossible to obtain the required degree of molecular order necessary for high resolution studies. One significant exception is the light-dependent proton pump, bacteriorhodopsin, which naturally forms two-dimensional crystals, a property elegantly exploited by Henderson and Unwin in their revolutionary work on the use of unstained samples and image processing in electron microscopy. This protein is equally well behaved spectroscopically and has over the past few years been the subject of a technique that promises
Peter J. Smith is a Reader in the Department of Earth Sciences at the Open University.

for microearthquakes on the Rivera fracture zone (Prothero et al. Nature, 262, 121; 1976), the March 1969 earthquake swarm in the Gulf of California (Thatcher J. geophys. Res. $77,1549 ; 1972)$, large ridge crest earthquakes (Solomon Eos, 57, 954; 1976), large transform fault earthquakes (Burr \& Solomon J. geophys. Res. in the press) and one or two other events. In spite of the wide range of data (4 orders of magnitude in fault length, 11 in seismic moment) the data points lie remarkably close to a straight line. There is some scatter about the imaginary regression line, and there is a suggestion of deviation from linearity at the largeearthquake end of the spectrum. But there are no large deviations from the general trend, and the triple junction earthquakes are no exception.

In other words, "the triple junction earthquakes have moments and fault lengths which scale as if the events occurred on a normal spreading center system"; and so, surprisingly perhaps, "the character of the earthquakes near the RRR triple junction in the central Indian Ocean is not demonstrably different from that on other spreading center boundaries". The inference that Solomon et al. draw is that any anomalies in the thermal structure or stress fields associated with the triple junction must be confined either to depths greater than that within which the earthquakes are generated or to a small zone surrounding the junction of no more than a few tens of kilometres across.

to bridge the structure-kinetics gap, resonance Raman spectroscopy.

Bacteriorhodopsin is a small protein spanning the membrane. Its chromophore, retinal, is attached to a lysyl side chain as a Schiff base. When light is absorbed by the retinal a photochemical cycle is initiated in which several transient species, with different absorption properties, have been identified and characterised kinetically. During the cycle a proton is released from the external surface of the membrane and one taken up at the cyto- 